\title{
VÍNCULOS TRANSNACIONAIS E MEDIAÇÕES CULTURAIS: a livraria Mestre Jou como distribuidora da editora Fondo de Cultura Económica no Brasil (1952-1965) ${ }^{1}$
}

\section{VÍNCULOS TRANSNACIONALES Y MEDIACIONES CULTURALES: la librería Mestre Jou como distribuidora de la editorial Fondo de Cultura Económica en Brasil (1952-1965)}

\section{TRANSNATIONAL LINKS AND CULTURAL MEDIATIONS: the "Mestre Jou" bookshop as distributor of the "Fondo de Cultura Económica"[Fund of Economic Culture] publishing house in Brazil(1952-1965).}

\author{
Bruna Marinho Valle Roriz ${ }^{2}$ \\ Universidade Federal de Minas Gerais (UFMG) \\ Luciano Mendes de Faria Filho ${ }^{3}$ \\ Universidade Federal de Minas Gerais
}

\begin{abstract}
Resumo: A editora mexicana Fondo de Cultura Económica (FCE), fundada em 1934, iniciou, já nos anos 1940, um movimento de expansão rumo ao sul do continente, incentivada por objetivos comerciais e por uma declarada missão de integração cultural da América Latina. Considerando tal contexto, este artigo é parte de uma pesquisa mais ampla sobre a circulação dos livros do FCE no Brasil, por meio da atuação de sua distribuidora exclusiva, a Livraria Mestre Jou, entre os anos de 1952 e 1965. Como principais fontes, utilizamos o acervo das relações comerciais entre o FCE e a Mestre Jou, preservado pelo Arquivo Histórico do Fondo. Neste texto, enfocaremos, em primeiro lugar, os vínculos transnacionais mobilizados pelo FCE para estabelecer a representação exclusiva no Brasil, em 1952, considerando as viagens realizadas e os sujeitos envolvidos. Em segundo lugar, discutiremos brevemente as práticas de mediação cultural empreendidas por Felipe Mestre Jou na divulgação dos livros do FCE. A presente pesquisa contribui para a maior compreensão da oferta de leitura proporcionada pelas obras do Fondo de Cultura Económica aos potenciais leitores brasileiros e para a reflexão sobre a figura do livreiro como um agente cultural no universo dos impressos.
\end{abstract}

Palavras-chave: editoras latino-americanas; século XX; comércio livreiro; intelectuais; mediações culturais

\footnotetext{
${ }^{1}$ As pesquisas que resultaram na produção deste artigo contam com o apoio do CNPq e da FAPEMIG.

${ }^{2}$ Graduada em História pela Universidade Federal de Minas Gerais (UFMG), Brasil. Atualmente, cursa mestrado em Educação, linha de pesquisa em história da educação, sob orientação do Prof. Dr. Luciano Mendes de Faria Filho, pela mesma instituição. E-mail: bruna roriz@hotmail.com. ORCID: http://orcid.org/0000-0002-3567-0675.

3 Doutor em Educação e Professor Titular da UFMG. É pesquisador bolsista do CNPq e da FAPEMIG. E-mail: lucianomff@uol.com.br. ORCID: http://orcid.org/0000-0002-1023-7138.
}

Revista Tópicos Educacionais, Pernambuco, v. 27, n. 02, p. 234-251, 2021. ISSN: 2448-0215.

https://periodicos.ufpe.br/revistas/topicoseducacionais/index

DOI: 10.51359/2448-0215.2021.252694 


\section{REVISTA TóPICOS EduCACIONAIS \\ Revista do Programa de Pós-Graduação em Educação \\ da Universidade Federal de Pernambuco (UFPE)}

Resumen: La editorial mexicana Fondo de Cultura Económica (FCE), fundada en 1934, empezó, al inicio de los años 1940, un movimiento de expansión hacia el sur del continente, alentada por objetivos comerciales y por una declarada misión de integración cultural de Latinoamérica. Teniendo en cuenta tal contexto, este artículo forma parte de una investigación más amplia sobre la circulación de los libros del FCE en Brasil, por medio de la actuación de su distribuidora exclusiva, la Librería Mestre Jou, entre los años de 1952 y 1965. Como fuentes principales, utilizamos el acervo de las relaciones comerciales entre el FCE y la Mestre Jou, conservado por el Archivo Histórico del Fondo. En este texto, pondremos de relieve, en primer lugar, los vínculos transnacionales movilizados por el FCE para establecer la representación exclusiva en Brasil, en 1952, teniendo presente los viajes realizados y los sujetos involucrados. En segundo lugar, discutiremos brevemente las prácticas de mediación cultural emprendidas por Felipe Mestre Jou en la difusión de los libros del FCE. La presente investigación contribuye a la comprensión de la oferta de lectura proporcionada por las obras del Fondo a potenciales lectores brasileños y a la reflexión sobre la figura del librero como un agente cultural en el universo de los impresos.

Palabras clave: editoriales latinoamericanas; siglo XX; comercio librero; intelectuales; mediaciones culturales

Abstract: The mexican publishing house Fondo de Cultura Económica (FCE), founded in 1934 begun, in the 1940 's an expansion towards the south of the continent, encouraged by commercial goals and by a declaration of cultural integrarion in Larin América. Considering this context, this communication is part of a bigger research about the circulation of the FCE's books in Brazil, through it's only distributor, the "Mestre Jou" bookshop, between the years of 1952 and 1965. As main sources, we used the archive of commercial relations between the FCE and the "Mestre Jou", preserved by the Historical Archive of the Fondo de Cultura Económica. In this text, we will focus first on the transnational links mobilized by the FCE to establish the exvlusive representatuve in Brazil, in 1952, considering the travels made and the people envolved. Second, we will discuss briefly the cultural mediation practices used by Felipe Mestre Jou in the advertising of the FCE's books. This research contributes for a greater comprehension of what the FCE's works had to offer to potential brazilian readers and for the reflection about the figure of the book seller as a cultural agent in the universe of printed goods.

Key words: latin publishing houses, 20th century, book commerce, intelectuals, cultural mediations

\section{Apresentação}

Há alguns anos a autora e o autor deste artigo vêm se dedicando ao estudo sobre as representações do Brasil em países latino-americanos de língua espanhola. Os primeiros trabalhos realizado foram sobre as representações do Brasil na Argentina na primeira metade do século XX (FARIA FILHO; RORIZ, 2012; 2015). Em seguida, nosso olhar voltou-se para o México (FARIA FILHO; MARTÍNEZ, 2021).

Este artigo é parte desta pesquisa mais ampla sobre as representações do Brasil na América Latina, ainda em desenvolvimento, tratando, agora, mais especificamente, da publicação de autores

Revista Tópicos Educacionais, Pernambuco, v. 27, n. 02, p. 234-251, 2021. ISSN: 2448-0215. https://periodicos.ufpe.br/revistas/topicoseducacionais/index DOI: $10.51359 / 2448-0215.2021 .252694$ 


\section{REVISTA TóPICOS EDUCACIONAIS \\ Revista do Programa de Pós-Graduação em Educação \\ da Universidade Federal de Pernambuco (UFPE)}

brasileiros no México (FARIA FILHO, 2021) e da circulação dos livros da editora mexicana Fondo de Cultura Económica (FCE) no Brasil entre os anos de 1952 e 1965. No texto, buscamos compreender a atuação da distribuidora exclusiva do Fondo, a Livraria Mestre Jou, na comercialização e na divulgação dos livros da editora mexicana durante o período delimitado e examinar em que medida o livreiro Felipe Mestre Jou desempenhou uma função mediadora entre o FCE e a intelectualidade brasileira.

A circulação é aqui entendida, de acordo com Robert Darnton (2010), como uma fase do "circuito das comunicações" que torna possível o ato de ler. Em interação com a produção dos livros e com a apropriação do escrito pelos leitores, a dimensão da circulação engloba os processos e os sujeitos que possibilitam a disponibilidade de objetos de leitura em diferentes espaços. Nessa perspectiva, a presente pesquisa contribui para a maior compreensão da oferta de leitura proporcionada pelas obras do Fondo de Cultura Económica aos potenciais leitores brasileiros. Além disso, auxilia no entendimento das estratégias de divulgação empreendidas por livreiros, posto que "[...] é preciso estudar melhor o livreiro enquanto agente cultural, o intermediário entre a oferta e a demanda em seu principal ponto de conexão. "(DARNTON, 2010, p. 143).

Os livros, ademais, podem circular para além das fronteiras estabelecidas pelas nações. Nessa perspectiva, nas duas últimas décadas, investigações que se voltam para a história do livro e da leitura na América Latina, considerando aqui as com enfoque no âmbito editorial, têm apontado para as vantagens de se adotar uma perspectiva de análise ampliada, que transcenda os espaços nacionais e busque identificar as conexões entre projetos editoriais, sujeitos e materiais escritos nas redes editoriais latino-americanas (DIEGO, 2016; SUBERCASEAUX, 2010) ou no "campo editorial iberoamericano"4 (SORÁ, 2017). Tal perspectiva não implica abandonar a formulação de problemas que tenham como referência os espaços nacionais, mas sim em situá-los nas redes transnacionais que se

\footnotetext{
${ }^{4}$ Em geral, as regras dos mercados editoriais são nacionais. Entretanto, Gustavo Sorá (2017) argumenta que algumas editoras transcendem os espaços nacionais, exportando sua produção para outros países e desenvolvendo iniciativas e alianças que configuram um "campo editorial transnacional". Por ser possível detectar esse movimento entre países da América Hispânica e entre eles e o Brasil, identifica-se, então, a formação de um "campo editorial ibero-americano".

Revista Tópicos Educacionais, Pernambuco, v. 27, n. 02, p. 234-251, 2021. ISSN: 2448-0215. https://periodicos.ufpe.br/revistas/topicoseducacionais/index DOI: 10.51359/2448-0215.2021.252694
} 


\section{REVISTA TópICOS EducaCiOnaIS \\ Revista do Programa de Pós-Graduação em Educação \\ da Universidade Federal de Pernambuco (UFPE)}

configuram através do continente cultural latino-americano. ${ }^{5}$ Nesse sentido, ao analisar a circulação de livros de editoras latino-americanas que se expandiram para além dos mercados nacionais, como a mexicana Fondo De Cultura Económica, mostra-se promissor incorporar a perspectiva transnacional. ${ }^{6}$

A delimitação temporal da presente investigação se inicia em 1952, ano em que a Mestre Jou se torna a distribuidora exclusiva do Fondo no Brasil. A documentação acessada informa que a representação se manteve até o ano de 1974 e que, desde o fim dos anos 1950, a Mestre Jou alertava para o aumento das traduções de obras constantes do catálogo do FCE por editoras brasileiras. Ainda assim, definimos 1965 como a delimitação temporal final, ano em que o próprio Fondo entra em crise por ocasião da demissão do Diretor Arnaldo Orfila Reynal, à frente da casa editorial de 1948 a 1965. Destituído em razão de seus posicionamentos políticos, mas sob a alegação de ser estrangeiro, Orfila Reynal logo funda a editora Siglo XXI, que atuaria como concorrente do Fondo de Cultura Económica. A demissão acarretou, ademais, a substituição de grande parte do corpo técnico do FCE, transformações no programa editorial e o enfraquecimento da projeção cultural da editora no continente. $^{7}$

A opção por tal delimitação temporal considerou a mencionada ruptura na trajetória da editora, mas também a percepção de que, durante o período em que foi possível realizar as consultas ao acervo, seria inviável acessar todo o volume documental existente sobre as relações com o Brasil até o ano de

\footnotetext{
${ }^{5}$ Adotamos, em alguns pontos, as expressões "continente cultural" ou "geografia cultural" para nos referir à América Latina, comuns na bibliografia sobre essa região, com o intuito de frisar que América Latina não é um dado geográfico e sim uma unidade constituída histórico e culturalmente. Discussão presente em Hilda Sabato (2015).

${ }^{6} \mathrm{~A}$ respeito da história transnacional, entendida como uma abordagem que pretende romper com a ideia de nação como o rígido marco espacial organizador das pesquisas em História, nos valemos das reflexões presentes em Prado (20112012), Purdy (2011) e Weinstein (2013).

${ }^{7}$ Arnaldo Orfila Reynal (1897-1997) era de nacionalidade argentina e químico de formação. Atuou como gerente da sucursal argentina do FCE de 1945 a 1948 e como diretor do Fondo de 1948 a 1965. Orfila Reynal foi destituído da direção do FCE em novembro de 1965, durante o governo de cunho autoritário do presidente mexicano Gustavo Díaz Ordaz (19641970). A demissão de Orfila Reynal da direção Editorial da FCE resultou numa intensa mobilização da intelectualidade mexicana e de várias outras partes do mundo para a denúncia do autoritarismo do Governo Mexicano, principal responsável pela Editora, e, mais do que isso, na oferta de recursos financeiros para a fundação da Editora Siglo XIX, casa editorial de grande prestígio na América Latina nas décadas seguintes. A este respeito, ver o trabalho de Sorá (2017). Sobre o contexto da demissão e as relações entre edição e política, ver Sorá (2008). Sobre as modificações ocorridas na editora após a mencionada demissão, ver Arciniega (1996).
}

Revista Tópicos Educacionais, Pernambuco, v. 27, n. 02, p. 234-251, 2021. ISSN: 2448-0215.

https://periodicos.ufpe.br/revistas/topicoseducacionais/index

DOI: $10.51359 / 2448-0215.2021 .252694$ 


\section{REVISTA TóPICOS EduCACIONAIS \\ Revista do Programa de Pós-Graduação em Educação \\ da Universidade Federal de Pernambuco (UFPE)}

1974. ${ }^{8}$ Acrescenta-se ainda o entendimento de que o aumento das traduções das obras do catálogo do FCE por editoras brasileiras, a partir do final dos anos 1950, não é um evento e sim um processo paulatino, cujas descontinuidades devem ser analisadas durante alguns anos.

No que se refere às fontes analisadas, nos valemos do acervo das relações comerciais entre o FCE e a Livraria Mestre Jou, preservado pelo Arquivo Histórico do Fondo de Cultura Económica. Tal documentação é composta por listas de pedidos; avisos de devolução de livros; notas fiscais; listas de livros endereçados a jornalistas para publicidade e alguns demonstrativos de vendas organizados por coleção. São dados que não resolvem a questão referente a quantos exemplares de obras o FCE vendeu no Brasil durante o período pesquisado, mas lançam luz sobre as formas como ocorreu a circulação dessas obras, informam sobre os títulos comercializados e nos aproximam de alguns dados quantitativos.

O acervo é ainda composto pela correspondência comercial entre a Livraria Mestre Jou e o FCE, contendo as cartas enviadas e recebidas. A documentação epistolar versa sobre as tratativas comerciais, as características do mercado livreiro do Brasil, assim como as dificuldades enfrentadas na logística de envio dos livros e na transferência de divisas entre Brasil e México. Do mesmo modo, a correspondência trata das estratégias de divulgação empreendidas pela Mestre Jou e nos fornece elementos para analisar como Felipe Mestre articulava para publicar, em jornais e revistas, resenhas de livros do FCE escritos por diferentes intelectuais brasileiros.

De forma complementar, recorremos a outros documentos produzidos pelo FCE, como os catálogos da editora no período de interesse e as atas das reuniões da Junta de Governo de 1950 a 1965. Afinal, os catálogos permitem conhecer o rol de obras editadas, enquanto as atas registram discussões administrativas mais amplas, entre elas as que impactaram nas relações comerciais com o Brasil. ${ }^{9}$

Tendo em conta a mencionada documentação, nos perguntamos: como se deu a atuação da Livraria Mestre Jou na circulação das obras do FCE no Brasil? Quais foram as ações para iniciar a

\footnotetext{
${ }^{8}$ As consultas ao Arquivo Histórico e à Biblioteca Gonzalo Robles do Fondo de Cultura Económica, localizados na Cidade do México, ocorreram durante o mês de novembro de 2020 e se realizaram em caráter extraordinário em função da pandemia da Covid-19. Agradecemos aos funcionários do Arquivo e da Biblioteca por nos receber com enorme presteza e cortesia.

${ }^{9}$ Durante o período pesquisado, a editora era gerida por uma Junta de Governo, que tomava as decisões de forma coletiva.

Revista Tópicos Educacionais, Pernambuco, v. 27, n. 02, p. 234-251, 2021. ISSN: 2448-0215. https://periodicos.ufpe.br/revistas/topicoseducacionais/index
} DOI: $10.51359 / 2448-0215.2021 .252694$ 


\section{REVISTA TóPICOS EduCACIONAIS \\ Revista do Programa de Pós-Graduação em Educação \\ da Universidade Federal de Pernambuco (UFPE)}

representação exclusiva? Qual a oferta de leitura proporcionada pelo FCE aos potenciais leitores brasileiros, durante o período analisado, ou quais os títulos apresentaram boa ou má acolhida comercial? Quais as práticas de mediação empreendidas por Felipe Mestre Jou na divulgação dos livros do FCE e nas trocas culturais entre a editora mexicana e a intelectualidade brasileira? Essas são as questões que guiam o desenvolvimento da investigação e, dentre elas, nos propomos a analisar dois pontos neste artigo: primeiramente, os vínculos transnacionais mobilizados pelo FCE para estabelecer a distribuição exclusiva no Brasil, considerando as viagens realizadas e os sujeitos envolvidos; em segundo lugar, algumas breves aproximações no que concerne às práticas de mediação cultural desenvolvidas pelo livreiro Felipe Mestre Jou na divulgação dos livros da editora mexicana. Antes, contudo, nos parece necessário uma breve contextualização.

\section{Breve contextualização: a fundação e a expansão comercial do Fondo de Cultura Económica}

Fundada em 1934, por iniciativa de um grupo de professores de ensino universitário e tendo à frente o intelectual Daniel Cosío Villegas ${ }^{10}$, a editora mexicana Fondo de Cultura Económica surgiu, a princípio, com a finalidade de suprir a carência de obras especializadas traduzidas para o espanhol. A Escola de Economia da Universidade Nacional Autónoma de México (UNAM) havia sido fundada em 1929 e a escassez de textos traduzidos impunha uma barreira aos estudantes que não liam em idiomas estrangeiros. Alargando o seu objetivo inicial, já no início dos anos 1940, o Fondo apresentava um catálogo de traduções inovador na área de humanidades que logo se somou à publicação de estudos sobre o México e a América Hispânica e a coleções de literatura. É nesse período que a editora inicia um movimento de expansão rumo ao sul do continente, incentivado por objetivos comerciais, mas também por uma declarada missão de integração cultural da América Latina. ${ }^{11}$

Sobre isso, o trabalho de Claudio Maiz e Alvaro Fernández Bravo (2009) aporta questões importantes. Os autores argumentam que, no começo do século XX, identifica-se a formação de uma comunidade de discurso em torno da ideia de hispanismo, que, entre outros, encontrou no Colegio de

${ }^{10}$ Daniel Cosío Villegas (1898-1976) era economista, professor, escritor e também atuou como diplomata e editor. Cosío Villegas dirigiu o FCE de 1934 a 1948, quando se licenciou para realizar uma pesquisa nos Estados Unidos.

${ }^{11}$ A fundação e a trajetória do FCE foram exploradas em profundidade nos trabalhos de Arciniega (1996) e de Sorá (2017, p. 53-99).

Revista Tópicos Educacionais, Pernambuco, v. 27, n. 02, p. 234-251, 2021. ISSN: 2448-0215. https://periodicos.ufpe.br/revistas/topicoseducacionais/index DOI: 10.51359/2448-0215.2021.252694 


\section{REVISTA TóPICOS EduCACIONAIS \\ Revista do Programa de Pós-Graduação em Educação \\ da Universidade Federal de Pernambuco (UFPE)}

México, instituição cuja trajetória possui relação com o FCE, um dos seus espaços de vínculo. ${ }^{12} \mathrm{~A}$ partir do início da guerra fria, entretanto, o hispanismo foi se ampliando em direção à perspectiva de América Latina “[...] que reemplazó su lugar y fortaleció lazos ya existentes en torno a una nueva red latino-americana." (MAIZ; BRAVO, 2009, p. 18).

Atentar-se para a existência de uma articulação de discursos e práticas, ao longo do século XX, que foi construindo a ideia de América Latina como unidade cultural auxilia a situar as iniciativas desenvolvidas pelo Fondo de Cultura Económica já a partir dos anos 1940. Os empreendimentos da editora como as coleções Tierra Firme, inaugurada em 1944, e Biblioteca Americana, iniciada em 1947, podem ser compreendidos como parte da "[...] red americanista que prefigura la fundación del latinoamericanismo [...]" (MAIZ; BRAVO, 2009, p. 30). Ademais, a vocação americanista do FCE transcendeu o seu catálogo. Conforme analisado por José Luís de Diego (2019), ao tomarmos o americanismo como um conjunto de ideias, mas também de práticas, é possível percebê-lo nas iniciativas de expansão comercial da editora. $\mathrm{O}$ autor frisa que "[...] el americanismo ya se puede encontrar en el catálogo, pero también en las batallas ideológicas y en la lucha por la hegemonía en un mercado específico." (DIEGO, 2019, p. 58).

Nessa linha, estudos como o de Víctor Díaz Arciniega (1996) e de Gustavo Sorá (2017) indicam que o catálogo de traduções sem concorrência em ciências humanas unido à expansão do Fondo pelo continente propiciou o acesso ao "saber estrangeiro"13 por parte dos potenciais leitores que não dominavam o francês ou o inglês (ARCINIEGA, 1996) e sugerem que as gerações intelectuais latinoamericanas, dos anos 1930, 1940 e 1950, “[...] parecen haberse formado con ciertas experiencias de lectura común [...]" (SORÁ, 2017, p. 77). Tais observações são corroboradas pelo depoimento do intelectual brasileiro Antônio Cândido, proferido na inauguração da sucursal do FCE em São Paulo, em 1991:

${ }^{12}$ O Colegio de México teve como antecedente a Casa de España, instituição criada nos moldes de um centro de estudos para receber intelectuais que se exilaram após a Guerra Civil Espanhola (1936-1939). A casa funcionou no mesmo edifício do Fondo de Cultura Económica, tendo Alfonso Reyes (1889-1955) como diretor e Daniel Cosío Villegas, diretor do FCE, como secretário. Em 1940, a Casa de España se transformou em Colegio de México, uma instituição voltada para atividades educacionais e investigativas com instalações próprias e cujos membros se estenderam para além dos intelectuais espanhóis exilados. Sobre isso, ver Javier Garcíadiego (2015).

13 Sobretudo obras europeias e estadunidenses.

Revista Tópicos Educacionais, Pernambuco, v. 27, n. 02, p. 234-251, 2021. ISSN: 2448-0215.

https://periodicos.ufpe.br/revistas/topicoseducacionais/index

DOI: $10.51359 / 2448-0215.2021 .252694$

(1) Esta obra está licenciada com uma Licença Creative Commons

Atribuição 4.0 Internacional. 


\section{REVISTA TóPICOS EDUCACIONAIS}

Revista do Programa de Pós-Graduação em Educação

da Universidade Federal de Pernambuco (UFPE)

Nos anos de 1930, 1940 e mesmo 1950 tínhamos pouca bibliografia no setor das ciências humanas, além de estudos específicos sobre o Brasil. Por isso, muitas das grandes obras da cultura nos foram proporcionadas por editoras de língua espanhola, como Losada, Espasa-Calpe de Buenos Aires, mas sobretudo Fondo de Cultura Económica, que trouxe grandes textos de filosofia, sociologia, economia, antropologia, história, teoria da arte e da literatura. Eram obras de Max Weber, Mannheim, Toënnies, Dilthey, Cassirer, Ermatinger, Alfonso Reyes e tantos outros. São inesquecíveis as capas coloridas dos livros: verdes, vermelhas, amarelas, azuis, rosadas, brancas, formando uma espécie de grande arco íris cultural que ligava simbolicamente os países da América Latina." (CÂNDIDO, 1993, p. 54-55 apud SORÁ, 2007, p. 541).

A presença do Fondo de Cultura Económica no mercado livreiro do Brasil ganha contornos significativos devido à diferença linguística. Há que se ter em conta também que, entre as décadas de 1930 e 1960, o Brasil vivenciou um processo de institucionalização universitária, que abarcou, inclusive, a área das ciências sociais (MICELI, 2001). Além disso, a bibliografia aponta que o mercado editorial local não possuía como foco principal as traduções de obras de ciências humanas e sim os livros de literatura, didáticos ou sobre a realidade brasileira (HALEWELL, 1985; PONTES, 2001). Uma exceção seria a coleção Biblioteca de Ciências Sociais, publicada pela Editora Martins entre 1943 e 1950, na qual editaram-se 11 títulos de antropólogos e sociólogos estrangeiros (PONTES, 2001, p. 458-459). Dois desses títulos foram também editados pelo Fondo de Cultura Económica na mesma época. ${ }^{14}$ As editoras universitárias, por sua vez, só viriam a se consolidar no Brasil na década de 1980 (MARQUES NETO; ROSA, 2010).

No mencionado trabalho recente cujo foco são as relações entre a intelectualidade brasileira e o FCE nos anos de 1940 e 1950, Faria Filho (2021) argumenta que o Brasil se configurou como um mercado consumidor importante para a editora. O autor destaca o papel da Livraria Mestre Jou e do livreiro Felipe Mestre Jou não apenas na comercialização, como também no desempenho de uma função mediadora entre intelectuais brasileiros e o FCE. Assim, tendo em conta as potencialidades apontadas pela bibliografia e pelas fontes já consultadas, consideramos a hipótese de que a circulação dos livros do Fondo no Brasil proporcionou uma oferta de leitura importante à educação intelectual brasileira, ao facilitar o acesso a obras especializadas traduzidas para o espanhol. Como se deram,

${ }^{14}$ Pesquisa realizada no Sistema de Bibliotecas da Universidade Federal de Minas Gerais (UFMG) e no Catálogo Histórico do FCE (2009).

Revista Tópicos Educacionais, Pernambuco, v. 27, n. 02, p. 234-251, 2021. ISSN: 2448-0215.

https://periodicos.ufpe.br/revistas/topicoseducacionais/index

DOI: $10.51359 / 2448-0215.2021 .252694$

(c) (i) Esta obra está licenciada com uma Licença Creative Commons

Atribuição 4.0 Internacional. 


\section{REVISTA TóPICOS Educacionais \\ Revista do Programa de Pós-Graduação em Educação \\ da Universidade Federal de Pernambuco (UFPE)}

contudo, as tratativas para iniciar a representação exclusiva do FCE, no Brasil, pela Livraria Mestre Jou?

\section{O FCE no Brasil: início da distribuição exclusiva pela Livraria Mestre Jou}

Em janeiro de 1945, o Fondo inaugura, na Argentina, a sua primeira sucursal internacional, tendo como gerente, Arnaldo Orfila Reynal, que, já a partir de 1948, transladaria ao México para se tornar o editor do FCE. ${ }^{15}$ Em 08 de março de 1952, Orfila Reynal escreve uma carta à María Elena Satostegui ${ }^{16}$, contadora da sucursal argentina do FCE, para instruí-la sobre as gestões comerciais que ela deveria realizar no Brasil com a finalidade de estabelecer uma representação exclusiva para a venda dos livros da editora mexicana. Poucos meses após visitar o Rio de Janeiro e São Paulo, a contadora viajaria também ao Chile com o objetivo de efetuar tratativas comerciais naquele país.

Na mencionada carta, Orfila Reynal expõe um breve resumo das difíceis relações comerciais com o Brasil até aquele momento, que podem ser sintetizadas da seguinte forma: a primeira distribuidora do FCE foi a Casa Herrera, seguida pela Civilização Brasileira, que representou a editora mexicana de 1947 a 1949, e logo pela Livraria Globo, que atuou como representante de fins de 1949 a meados de 1951. ${ }^{17}$ Em seguida, Orfila Reynal informa que o Fondo estava em negociação com duas livrarias interessadas em representá-lo: a Mestre Jou e a Livro Ibero Americana.

A Livraria Mestre Jou não foi, portanto, a primeira representante do Fondo de Cultura Económica no Brasil, mas foi a que desenvolveu uma relação comercial mais duradoura. Afinal, outorgada a representação exclusiva em 31 de março de 1952, a Mestre Jou seguiu atuando na distribuição dos livros da casa editorial mexicana por cerca de mais duas décadas. Nesse sentido, a busca por uma nova representação no Brasil, no ano de 1952, correspondia, conforme frisado por

${ }^{15}$ A respeito da sucursal argentina do Fondo de Cultura Económica durante a gestão de Arnaldo Orfila Reynal (1945-1948) e de Delia Etcheverry (1948-1956), ver a dissertação de mestrado de Anguiano (2019).

${ }^{16}$ María Elena Satostegui (1916-1985) atuou como contadora da sucursal argentina do FCE ao menos desde 1948 e até 1957, quando sucedeu a Delia Etcheverry no cargo de gerência. Ela foi a encarregada de organizar a sucursal chilena da editora, em 1953, e a sucursal espanhola, em 1963. Satostegui e Ofila Reynal foram casados até 1951. Para mais informações a respeito de sua trajetória, ver Sorá (2017, p. 129-143).

${ }^{17}$ Nos arquivos do Fondo, não há acervos preservados sobre as representações anteriores.

Revista Tópicos Educacionais, Pernambuco, v. 27, n. 02, p. 234-251, 2021. ISSN: 2448-0215.

https://periodicos.ufpe.br/revistas/topicoseducacionais/index

DOI: $10.51359 / 2448-0215.2021 .252694$ 


\section{REVISTA TóPICOS EduCaCiONAIS \\ Revista do Programa de Pós-Graduação em Educação \\ da Universidade Federal de Pernambuco (UFPE)}

Orfila, ao intento de "[...] hacer esta cuarta prueba en ese país, a ver si tenemos mejores resultados." (MARÍA..., 1952-1956).

Sobre a trajetória da empresa Mestre Jou, cabe mencionar que essa iniciou suas atividades comerciais na segunda metade da década de 1940. Por meio de pesquisa realizada nos Diários Oficiais da União brasileiros e nos Diários do Estado de São Paulo, é possível encontrar dados da Mestre Jou e Cia. Ltda a partir de 1946 (BRASIL...,1946) e apreender que se tratava de uma empresa do ramo de importações e exportações diversas, mas que, provavelmente, incluía o comércio de livros ao menos desde 1949. ${ }^{18}$ A princípio situada em São Paulo, a Mestre Jou contou com uma filial no Rio de Janeiro ao menos desde 1951 e, a partir de 1958, começou a atuar também como editora. Já Felipe Mestre Jou, segundo informações obtidas informalmente com sua família, nasceu em 1903, na província de Tarragona, Espanha, e se transladou ao Brasil, como exilado da Guerra Civil Espanhola (1936-1939), após uma estância no Chile. Ele esteve à frente da livraria e editora Mestre Jou até falecer, em setembro de 1980.

Dando continuidade às orientações para iniciar a representação exclusiva do FCE no Brasil, Orfila Reynal explicita, ainda na carta que remeteu à Satostegui em 08 de março de 1952, que o Fondo se inclinava a concretizar a representação com a Livraria Mestre Jou porque essa, não diz na pessoa de quem, já havia viajado ao México e visitado a editora, provavelmente, em 1949, mas sobretudo porque a Mestre Jou havia sido recomendada por Francisco Giner de los Ríos, que era amigo de seu dono e gerente: Felipe Mestre Jou. Giner de $\operatorname{los}$ Ríos $^{19}$ foi um dos intelectuais exilados no México, após a Guerra Civil Espanhola, que encontrou espaço de atuação no Colegio de México e no FCE. É de autoria dele, inclusive, um dos livros que inaugurou a Coleção de poesias e contos Tezontle, em 1940. Como

\footnotetext{
${ }^{18} \mathrm{Na}$ carta de Arnaldo Orfila Reynal a María Elena Satostegui datada de 08 de março de 1952, Orfila menciona que o FCE efetuou vendas de livros a Mestre Jou, acreditava ele, em 1949. Além disso, dos Diários Oficiais do Estado de São Paulo constam vendas da Mestre Jou a Universidade de São Paulo (USP) desde 1950, ainda que os Diários não especifiquem o tipo de produto vendido. Dessas informações, infere-se que, por mais que a Mestre Jou tenha iniciado suas atividades importando e exportando produtos diversos, os livros, desde o início, parecem ter composto a gama de artigos comercializados pela empresa.

${ }^{19}$ Francisco Giner de los Ríos (1917-1995) foi um poeta espanhol exilado, no México, em 1939. Era sobrinho neto do também Francisco Giner de los Ríos (1839-1915), esse último fundador da Institución Libre de Enseñanza, na Espanha, em 1876. Uma breve trajetória de Francisco Giner de los Ríos (sobrinho neto) pode ser encontrada em Valender e Leyva (2006, p. 423-436).
}

Revista Tópicos Educacionais, Pernambuco, v. 27, n. 02, p. 234-251, 2021. ISSN: 2448-0215. https://periodicos.ufpe.br/revistas/topicoseducacionais/index DOI: $10.51359 / 2448-0215.2021 .252694$ 


\section{REVISTA TóPICOS EduCACIONAIS \\ Revista do Programa de Pós-Graduação em Educação \\ da Universidade Federal de Pernambuco (UFPE)}

mencionado, Felipe Mestre Jou também foi um espanhol exilado em razão da Guerra Civil Espanhola, ainda que não tenha estabelecido moradia no México e sim no Brasil. Não sabemos em que circunstâncias Giner de los Ríos e Mestre Jou se conheceram, mas a menção à amizade entre eles, na carta, demonstra os vínculos entre os sujeitos situados em diferentes nações.

Orfila Reynal e María Elena Satostegui continuam a se corresponder durante toda a viagem da contadora ao Brasil, que se estendeu até meados de abril de 1952. Entre algumas reclamações relativas à demora nos correios ou a má qualidade da máquina de escrever de Satostegui, os missivistas vão se comunicando sobre os andamentos das negociações comerciais por meio de cartas manuscritas, manuscritas datilografadas e por bilhetes de telégrafo. Em carta de 21 de março, Satostegui informa que se reuniu com Felipe Mestre Jou e que, se houvesse autorização de Orfila Reynal, eles poderiam concretizar a representação exclusiva, o que foi autorizado em 31 de março. Da reunião, é relevante a descrição a respeito dos livros do FCE considerados invendíveis no Brasil:

Hemos analizado todos los títulos y según su opinión [de Felipe Mestre] más o menos el $50 \%$ es invendible en Brasil. Los que se refieren a problemas de América Latina, por ejemplo. Le interesa toda economía, historia, filosofía, sociología. (MARÍA..., 19521956).

María Elena Satostegui corrobora a avaliação do livreiro, argumentando que: "Yo también opino que el $90 \%$ de nuestro catálogo tiene valor permanente, pero para América Latina o para un Brasil de cultura más extendida." (MARÍA..., 1952-1956). As menções às temáticas que apresentariam boa acolhida comercial reforçam a hipótese de que o Brasil também carecia de livros especializados traduzidos, de modo que as traduções para o espanhol empreendidas pelo Fondo de Cultura Económica poderiam auxiliar a suprir a demanda existente. Ao mesmo tempo, as avaliações, ainda que sejam individuais, afirmam que os livros referentes aos "problemas da América Latina" não despertariam interesse nos potenciais leitores brasileiros, sugerindo que, nos anos 1950, o ideal de um conhecimento sobre a realidade latino-americana que se difundisse por todos os países dessa geografia cultural poderia não encontrar suficiente ressonância entre os estudiosos brasileiros. Satostegui, inclusive, não insere o Brasil em sua concepção de América Latina ao opinar que a maior parte do catálogo do FCE teria valor permanente para a América Latina ou para um Brasil de cultura mais ampla.

Revista Tópicos Educacionais, Pernambuco, v. 27, n. 02, p. 234-251, 2021. ISSN: 2448-0215. https://periodicos.ufpe.br/revistas/topicoseducacionais/index DOI: 10.51359/2448-0215.2021.252694 


\section{REVISTA TóPICOS EDUCACIONAIS \\ Revista do Programa de Pós-Graduação em Educação da Universidade Federal de Pernambuco (UFPE)}

Por fim, a análise de Felipe Mestre Jou a respeito de quais seriam os interesses dos leitores brasileiros reforça o entendimento do livreiro como um dos principais agentes situados entre a oferta $\mathrm{e}$ a demanda ou, em outras palavras, do livreiro como um dos mediadores que opera entre os saberes e a difusão dos saberes. ${ }^{20} \mathrm{Na}$ condição de distribuidor dos livros do FCE no Brasil, Felipe Mestre, no trecho acima e em outras passagens da correspondência comercial analisada ${ }^{21}$, indica e registra aquilo que, supostamente, seriam os gostos dos potenciais leitores brasileiros, ao mesmo tempo em que influencia no que é posto em circulação ao atuar na seleção das obras a serem distribuídas.

A difusão dos saberes, assim, ocorre quando atores do universo do livro atuam na disponibilização dos objetos impressos em determinado espaço e, de modo mais específico, se dá também quando desenvolvem práticas de divulgação desses objetos impressos. Conforme ressaltado por Eliana Dutra (2012, p. 1): “[....] analisar o percurso da edição e da divulgação dos livros exige que consideremos suas mediações intelectuais e a condição mesma dos livros como mediadores de cultura e de identidades." Tendo em conta essa perspectiva, propomos, em seguida, algumas aproximações em relação às ações de divulgação das obras do Fondo de Cultura Económica desenvolvidas pelo livreiro Felipe Mestre Jou.

\section{Algumas aproximações: a atuação a Livraria Mestre Jou na divulgação dos livros do FCE}

A pesquisa documental realizada até o momento informa que, além da comercialização de livros estritamente, a Livraria Mestre Jou empreendeu ações de divulgação das obras do FCE no Brasil, como a publicação de anúncios em jornais e revistas. Conforme frisado por Felipe Mestre Jou em carta a Arnaldo Orfila Reynal, de 14 de junho de 1954, “[...] ya sabe Ud. que mis excelentes relaciones con la Prensa me facultan publicar todo lo que Ud. me pida." (“54" MESTRE JOU...,1954). As atividades de divulgação, contudo, se estendiam para além da publicação de anúncios, uma vez que Felipe Mestre mobilizava intelectuais brasileiros para escrever resenhas dos livros do FCE em jornais e revistas -

20 O editor e o tradutor são outros agentes do universo dos impressos que atuam como mediadores entre o saber produzido e sua difusão.

${ }^{21}$ A carta que Felipe Mestre Jou remete a Orfila Reynal, em 07 de julho de 1953, e a carta que remete ao FCE, em 30 de outubro de 1954, são exemplos de outras passagens nas quais Mestre Jou avalia a colocação de determinadas obras da editora mexicana no mercado de livros brasileiro.

Revista Tópicos Educacionais, Pernambuco, v. 27, n. 02, p. 234-251, 2021. ISSN: 2448-0215.

https://periodicos.ufpe.br/revistas/topicoseducacionais/index

DOI: 10.51359/2448-0215.2021.252694 


\section{REVISTA TóPICOS EduCACIONAIS \\ Revista do Programa de Pós-Graduação em Educação da Universidade Federal de Pernambuco (UFPE)}

como O Tempo, O Diário de São Paulo e a Revista Anhembí - e para publicar nos periódicos do FCE, no México, como na Revista La Gaceta. ${ }^{22}$ Felipe Mestre cultivou o costume de mencionar, nas cartas enviadas ao FCE, as notícias e resenhas de livros que haviam sido publicadas na imprensa paulista e fluminense, tendo, algumas vezes, encaminhado os recortes anexos às missivas. ${ }^{23}$

Por sua vez, o Fondo enviava, por intermédio da Mestre Jou, exemplares de livros endereçados a determinados redatores e diretores de periódicos brasileiros com o objetivo de incrementar a publicidade. Sobre isso, chama atenção a especial colaboração do Sr. Luís Washington Vita, redator do Diário de São Paulo na época. ${ }^{24}$ Além de figurar nas listas de destinatários das obras enviadas para publicidade, Washington Vita atuou constantemente como resenhista dos livros editados pelo FCE e como tradutor de resenhas escritas originalmente em espanhol, ademais de publicar dez textos em $\mathrm{La}$ Gaceta, do FCE, durante o período por nós contemplado. ${ }^{25}$ Essas informações sinalizam a importância de aprofundar a pesquisa a respeito da dinâmica de publicação das resenhas e sobre a possível existência de uma rede de resenhistas brasileiros.

Ademais, conforme analisado por Luciano Mendes de Faria Filho (2021, p. 93-95), Felipe Mestre Jou colaborou com a organização da viagem de Arnaldo Orfila Reynal ao Brasil, em 1955, quando o recepcionou na Associação Brasileira de Imprensa e propiciou o diálogo com intelectuais como Josué de Castro, Lins do Rego e Celso Furtado. Já no aniversário de 25 anos do Fondo, a Mestre Jou impulsionou uma série de atividades, entre elas: a organização de vitrines com os dizeres "uma editora mexicana de âmbito continental"; uma entrevista de Felipe Mestre à emissora de rádio paulista A Gazeta e conferências, no Rio de Janeiro e em São Paulo, com a participação dos professores Cruz Costa, Sérgio Buarque de Holanda, Josué de Castro, entre outros. Esses são exemplos de atividades que apontam para o entendimento de que "[...] a atuação da Mestre Jou como distribuidora comportava,

${ }^{22}$ La Gaceta é um periódico mensal publicado pelo FCE, desde 1954, com o objetivo de divulgar os projetos e as publicações da casa editorial.

${ }^{23}$ É possível encontrar menções aos anúncios e resenhas publicadas na imprensa brasileira ao longo de toda a correspondência comercial do período de 1952 a 1965. Por isso, não especificamos quais as cartas tratam dessa temática.

${ }^{24}$ Luís Washington Vita (1921-1968) era paulista e bacharel em Direito. Além de redator no Diário de São Paulo, atuou como docente na Escola de Sociologia e Política de São Paulo. Faleceu em 1968, aos 47 anos.

${ }^{25}$ Busca realizada no Catálogo Analítico de La Gaceta, fornecido pela Biblioteca Gonzalo Robles do Fondo de Cultura Económica.

Revista Tópicos Educacionais, Pernambuco, v. 27, n. 02, p. 234-251, 2021. ISSN: 2448-0215.

https://periodicos.ufpe.br/revistas/topicoseducacionais/index

DOI: 10.51359/2448-0215.2021.252694

(i) Esta obra está licenciada com uma Licença Creative Commons

Atribuição 4.0 Internacional. 


\section{REVISTA TóPICOS EduCACIONAIS \\ Revista do Programa de Pós-Graduação em Educação \\ da Universidade Federal de Pernambuco (UFPE)}

também, ações de mediação com a intelectualidade brasileira nas quais a empresa brasileira atuava como uma representante da editora mexicana no Brasil. " (FARIA FILHO, 2021, p. 93).

Para melhor compreender a função mediadora exercida por Felipe Mestre Jou, importa mencionar o profícuo trabalho de Ângela de Castro Gomes e Patrícia Hansen (2016) a respeito da categoria analítica "intelectuais mediadores". As autoras propõem alargar os limites da definição de intelectuais, considerando-os como "[...] homens da produção de conhecimento e comunicação de ideias, direta ou indiretamente vinculados à intervenção político-social. " (GOMES; HANSEN, 2016, p. 10). Tal definição, por ter uma acepção ampla, englobaria os "mediadores culturais": sujeitos cuja atividade se volta para os processos de acesso e difusão de bens simbólicos para um público mais amplo ou de circulação de saberes de um espaço a outro, de uma época a outra ou de um código cultural a outro.

O mediador cultural, entretanto, não deve ser concebido como um mero transmissor, que apenas divulga os saberes sem nada acrescentar ou transformar. Ao contrário, ao comunicar bens simbólicos, o mediador também produz novos sentidos, posto que a atividade de comunicação requer criar formas de aproximação aos bens culturais já existentes, assim como desenvolver novos bens culturais na própria ação de comunicar. Se as práticas de mediação transformam e criam sentidos, o mediador pode ser concebido como um produtor de bens simbólicos e, por consequência, como um intelectual, conforme a acepção trabalhada por Gomes e Hansen (2016). Essa proposta analítica rompe com uma rígida e hierarquizada divisão entre intelectual "produtor" e "mediador", já que o último também cria. Em suma, "Com esses e outros sentidos inscritos em sua produção, aquilo que o intelectual 'mediou' tornase, efetivamente, 'outro 'produto': um bem cultural singular. " (GOMES; HANSEN, 2016, p. 8). Devido às potencialidades da análise empreendida pelas mencionadas autoras, incorporamos a categoria de "intelectual mediador" para interpretar as ações desenvolvidas pelo livreiro Felipe Mestre Jou em torno da comercialização e da divulgação dos livros do FCE no Brasil.

\section{Conclusão}

Conforme aclarado, a investigação referente à circulação dos livros da editora mexicana Fondo de Cultura Económica no Brasil, durante o período de 1952 e 1965, encontra-se em desenvolvimento.

Revista Tópicos Educacionais, Pernambuco, v. 27, n. 02, p. 234-251, 2021. ISSN: 2448-0215. https://periodicos.ufpe.br/revistas/topicoseducacionais/index DOI: $10.51359 / 2448-0215.2021 .252694$ 


\section{REVISTA TóPICOS EduCACIONAIS \\ Revista do Programa de Pós-Graduação em Educação \\ da Universidade Federal de Pernambuco (UFPE)}

Não obstante, já foi possível examinar algumas questões constitutivas de tal problema de pesquisa. De um lado, a troca epistolar entre Orfila Reynal e Satostegui, no contexto das negociações comerciais com o Brasil, revelam a existência de conexões que se estabelecem para além das fronteiras nacionais: do México, Orfila Reynal solicita que Satostegui, desde a Argentina, viaje ao Brasil e ao Chile. Ao mesmo tempo, Francisco Giner de los Ríos, exilado espanhol no México, recomenda al FCE a empresa de Felipe Mestre Jou, exilado espanhol no Brasil.

Por outro lado, as atividades de divulgação das obras do FCE sinalizam a existência de práticas de mediação por parte de Felipe Mestre Jou. O livreiro mediava trocas culturais entre intelectuais do Brasil e o Fondo de Cultura Económica. Sobretudo, Felipe Mestre mediava os livros, que são bens simbólicos, ao difundi-los para um público mais amplo por meio da promoção de ações culturais. Essas ações culturais, como visto, são criativas e produtoras de novos sentidos.

Neste intricado movimento dos sujeitos no mundo da cultura e no contexto de relações transnacionais, o multifacetado objeto livro se constitui, ao mesmo tempo, em mediador cultural e comercial entre sujeitos os mais diversos, ao mesmo tempo em que é objeto de atenção de práticas mediadoras de sujeitos postados em diferentes posições em redes de sociabilidades e circuitos comerciais. Nessa perspectiva, Felipe Mestre Jou pode ser compreendido como um mediador cultural e como um intelectual. A figura do livreiro como agente cultural e, no caso específico, como intelectual mediador é representativa porque chama a atenção para a imbricação entre interesses comerciais e culturais. O livreiro adentra o terreno da cultura, antes de tudo, porque o objeto que comercializa - o livro - é um objeto cultural.

\section{Referências Bibliográficas}

ANGUIANO, Francisco Joel Guzmán. La sucursal argentina del Fondo de Cultura Económica en sus primeros años: circuito editorial y prácticas (1945-1956). 2019. Tesis (Maestría en Historia) Facultad de Filosofía y Letras, Universidad Nacional Autónoma de México, México, 2019.

ARCINIEGA, Víctor Díaz. Historia de la Casa Fondo de Cultura Económica (1934-1994). México: Fondo de Cultura Económica, 1996.

Revista Tópicos Educacionais, Pernambuco, v. 27, n. 02, p. 234-251, 2021. ISSN: 2448-0215. https://periodicos.ufpe.br/revistas/topicoseducacionais/index DOI: 10.51359/2448-0215.2021.252694 


\section{REVISTA TóPICOS EDUCACIONAIS \\ Revista do Programa de Pós-Graduação em Educação \\ da Universidade Federal de Pernambuco (UFPE)}

DARTON, Robert. O que é a história dos livros? In: DARNTON, Robert. O beijo de Lamourette: mídia, cultura e revolução. São Paulo: Companhia das Letras, 2010. p. 122-149.

DIEGO, José Luis de. Libros y literatura en el espacio latinoamericano. In: FUNES, Leonardo (ed.). Hispanismos del mundo: diálogos y debates en (y desde) el Sur. Buenos Aires: Mino y Dávila, 2016. p. 87-106.

DIEGO, José Luis de. Redes intelectuales y proyectos editoriales en América Latina. In: DIEGO, José Luis de. Los autores no escriben libros: nuevos aportes a la historia de la edición. Buenos Aires: Ampersand, 2019. p. 53-79.

DUTRA, Eliana Freitas. Projetos editorias e exposições do livro no espaço latino-americano: intelectuais e trocas culturais: 1930-1940. In: PRIMER COLOQUIO ARGENTINO DE ESTUDIOS SOBRE EL LIBRO Y LA EDICIÓN, 2012, La Plata (Argentina). Anais... La Plata (Argentina): Universidad Nacional de La Plata, 2012. p. 01-21.

FARIA FILHO, Luciano Mendes. Uma brasiliana para América Hispânica: a editora Fondo de Cultura Económica e a intelectualidade brasileira (décadas de 1940/1950). Jundiaí: Paco Editorial, 2021.

FARIA FILHO, Luciano Mendes; MARTÍNEZ, Rosalía Meníndez. Representações do Brasil nos livros de história de américa mexicanos - 1933/1965. In: PEREIRA, Elaine Teixeira; FARIA FILHO, Luciano Mendes; DARO, Maria das Dores; BARRETO, Raylane A. Dias Navarro. (orgs). A educação nos projetos de Brasil: espaço público, modernização e pensamento histórico e social brasileiro nos séculos XIX e XX. Belo Horizonte: Fino Traço, 2021,

FARIA FILHO, Luciano Mendes; RORIZ, Bruna Marinho Valle. O Brasil para estrangeiro ler: livros publicados sobre o Brasil na Biblioteca Nacional de Maestros de Buenos Aires, 1900-1935. In: GIL, Natália; ZICA, Matheus da Cruz e; FARIA FILHO, Luciano Mendes de. (orgs.). Moderno, Modernidade e Modernização: a educação nos projetos de Brasil - século XIX e XX. Belo Horizonte: Mazza Edições, 2012. p. 53-80.

FARIA FILHO, Luciano Mendes; RORIZ, Bruna Marinho Valle. O Brasil para argentino ler: aproximações do livro El Brasil Intelectual: impresiones y notas literarias, de Garcia Mérou. In: MESQUITA, Ilka Miglio de; BARRETO, Raylane Andreza Dias NavarrO; NOGUEIRA, Vera Lúcia. (Orgs.). Moderno. modernidade e modernização: a educação nos projetos de Brasil - séc. XIX e XX. Belo Horizonte: Mazza Edições, 2015. p. 81-96.

GARCIADIEGO, Javier. Autores, editoriales, instituciones, y libros: estudios de historia intelectual. México: El Colegio de México, 2015. E-book.

Revista Tópicos Educacionais, Pernambuco, v. 27, n. 02, p. 234-251, 2021. ISSN: 2448-0215. https://periodicos.ufpe.br/revistas/topicoseducacionais/index DOI: $10.51359 / 2448-0215.2021 .252694$ 


\section{REVISTA TóPICOS EDUCACIONAIS \\ Revista do Programa de Pós-Graduação em Educação \\ da Universidade Federal de Pernambuco (UFPE)}

GOMES, Ângela Maria de Castro; HANSEN, Patrícia Santos. Apresentação: intelectuais, mediação cultural e projetos políticos: uma introdução para a delimitação do objeto de estudo. In: GOMES, Ângela Maria de Castro; HANSEN, Patrícia Santos. (orgs.). Intelectuais Mediadores: práticas culturais e ação política. Rio de Janeiro: Civilização Brasileira, 2016. p. 7-37.

HALLEWELL, Laurence. O livro no Brasil: sua história. São Paulo: Edusp, 1985.

MACHADO, Ubiratan. Pequeno guia histórico das livrarias brasileiras. São Paulo: Ateliê, 2008.

MAIZ, Claudio; FERNÁNDEZ BRAVO, Alvaro. Introducción. Los sistemas de religación en la literatura. In: MAIZ, Claudio; FERNÁNDEZ BRAVO, Alvaro (orgs.). Episodios en la formación de redes culturales en América Latina. Buenos Aires: Prometeo Libros, 2009. p. 11-45.

MARQUES NETO, José Castilho; ROSA, Flávio Garcia. Editoras universitárias: academia ou mercado? Reflexões sobre um falso problema. In: BRAGANÇA, Aníbal; ABREU, Márcia. (org.).

Impresso no Brasil: dois séculos de livros brasileiros. São Paulo: Editora Unesp, 2010. p. 331-347. MICELI, Sérgio. Condicionantes do desenvolvimento das Ciências Sociais. In: MICELI, Sérgio (org.). História das Ciências Sociais no Brasil. v. 1. São Paulo: Editora Sumaré, 2001. p. 91-134.

PRADO, Maria Lígia Coelho. América Latina: história comparada, histórias conectadas, história transnacional. Anuário n. 24, Escuela de Historia, Revista Digital n. 3, Facultad de Humanidades y Artes (UNR), p. 9-22, 2011-2012.

PONTES, Heloísa. Retratos do Brasil: editores, editoras, e "Coleção Brasiliana" nas décadas de 1930, 1940 e 1950. In: MICELI, Sérgio (org.). História das Ciências Sociais no Brasil. São Paulo: Editora Sumaré, 2001. v. 1. p. 419-476.

PURDY, Sean. A História comparada e o desafio da transnacionalidade. Revista de História Comparada. Rio de Janeiro, 6-1, p. 64-84, 2012.

SABATO, Hilda. Historia latinoamericana, historia de América Latina, Latinoamérica en la historia. Prismas. Revista de historia intelectual. Buenos Aires, n. 19, p. 135-145, 2015.

SORÁ, Gustavo. Misión de la edición para una cultura en crisis. El Fondo de Cultura Económica y el americanismo en Tierra Firme. In: JORNADAS INTERESCUELAS/DEPARTAMENTO DE HISTORIA, 11., 2007, San Miguel de Tucumán. Anais... San Miguel de Tucumán: Facultad de Filosofía y Letras. Universidad Tucumán, 2007. p. 1-30.

SORÁ, Gustavo. Edición y política. Guerra fría en la cultura latinoamericana de los años '60. Revista del Museo de Antropología, 1, p. 97-114, 2008.

Revista Tópicos Educacionais, Pernambuco, v. 27, n. 02, p. 234-251, 2021. ISSN: 2448-0215. https://periodicos.ufpe.br/revistas/topicoseducacionais/index DOI: $10.51359 / 2448-0215.2021 .252694$ 


\section{REVISTA TóPICOS EdUCACIONAIS \\ Revista do Programa de Pós-Graduação em Educação da Universidade Federal de Pernambuco (UFPE)}

SORÁ, Gustavo. Editar desde la izquierda en América Latina: la agitada historia del Fondo de Cultura Económica y de Siglo XXI. Buenos Aires: Siglo XXI, 2017.

SUBERCASEAUX, Bernardo. Editoriales y círculos intelectuales en Chile (1930-1950). In:

ALTAMIRANO, Carlos (org.). Historia de los intelectuales en América Latina: II. los avatares de la "ciudad letrada” en el siglo XX. Buenos Aires: Katz, 2010. p. 567-580.

VALENDER, James; LEYVA, Gabriel Rojo. Francisco Giner de los Ríos (1917-1995). In: VALENDER, James; LEYVA, Gabriel Rojo. (orgs.). Poetas del exilio español: Una antología. México: El Colegio de México, 2006. p. 423-424.

WEINSTEIN, Barbara. Pensando a história fora da nação: a historiografia da América Latina e o viés transnacional. Revista Eletrônica da ANPHLAC, n.14, p. 9-36, jan./jun. 2013.

\section{Referências Documentais}

BRASIL. Resumo dos documentos arquivados e registrados. Diário Oficial da União, Rio de Janeiro, seção I, 14 de novembro de 1946, p. 37.

CATÁLOGO analítico de la revista La Gaceta (1954-1962). México: Fondo de Cultura Económica, 1954-1962, 2018.

CATÁLOGO histórico (1934-2009). México: Fondo de Cultura Económica, 2009.

MARÍA Elena Satostegui. Caixa 45, Expediente 1, Clave 81/264. 1952-1956. (Expediente Brasil). Arquivo Histórico do Fondo de Cultura Económica, Cidade do México.

“53” MESTRE Jou and Co. LTD. Caixa 44, Expediente 21, Clave 81/172. 1953. (Expediente Brasil). Arquivo Histórico do Fondo de Cultura Económica, Cidade do México.

“54” MESTRE Jou and Co. LTD. Caixa 44, Expediente 22, Clave 81/172. 1954. (Expediente Brasil). Arquivo Histórico do Fondo de Cultura Económica, Cidade do México.

Recebido em 07 de dezembro de 2021. Aprovado em 07 de dezembro de 2021.

Revista Tópicos Educacionais, Pernambuco, v. 27, n. 02, p. 234-251, 2021. ISSN: 2448-0215. https://periodicos.ufpe.br/revistas/topicoseducacionais/index DOI: $10.51359 / 2448-0215.2021 .252694$ 